\title{
Short Communication: The normal karyotyping result of Indonesian native breed bull qualified for artificial insemination
}

\author{
GATOT CIPTADI ${ }^{1, \bullet}$, MUH NUR IHSAN ${ }^{1}$, VERONICA M. ANI NURGIARTININGSIH ${ }^{1}$, \\ IRSANTI PUTRI ARDYAH ${ }^{2}$, MUDAWAMAH MUDAWAMAH ${ }^{3}$ \\ ${ }^{1}$ Faculty of Animal Husbandry, Universitas Brawijaya. Jl. Veteran, Malang City 65145, East Java, Indonesia. Tel.: +62-341-553513, `email: \\ ciptadi@ub.ac.id \\ ${ }^{2}$ Program of Graduates, Department of Biology, Faculty of Mathematics and Natural Sciences, Universitas Brawijaya. Jl. Veteran, Malang City 65145, \\ East Java, Indonesia \\ ${ }^{3}$ Faculty of Animal Husbandry, Universitas Islam Malang. Jl. Mayjen Haryono No.193, Malang City 65144, East Java, Indonesia
}

Manuscript received: 12 July 2017. Revision accepted: 24 September 2017.

\begin{abstract}
Ciptadi G, Ihsan MN, Nurgiartiningsih VMA, Ardyah IP, Mudawamah M. 2017. Short Communication: The normal karyotyping result of Indonesian native breed bull qualified for artificial insemination. Biodiversitas 18: 1462-1467. Bali and Madura cattle are important native breed in Indonesia, both descendants of wild banteng (Bos javanicus). These breeds are categorized as a small type beef cattle, and are indigenous, well adapted and, have high resistance to diseases. The aims of this research were to analyze dendrograms of these breed and karyotype breeding bull selected for Artificial Insemination (AI). The result showed that the $2 \mathrm{n}$ diploid number of chromosome of all cattle was 60 and they were considered normal, based on the number and structure of chromosomes. Fiftyeight acrocentric autosomes and 2 sex chromosome were observed, including a submetacentric $\mathrm{X}$-large chromosome submetacentric and a small Y chromosome. Dendrogram analysis showed that Bali and Madura cattle were closely related and derived more from their ancestor wild banteng than from Java cattle. It is recommended to perform a chromosomal investigation of breeding bulls especially those used for freezing semen production and AI implementation.
\end{abstract}

Keywords: Abnormalities, Artificial Insemination, cattle, dendrogram, genetic, karyotyping

\section{INTRODUCTION}

In Indonesia, there are many native breeds, and unidentified breeds of ruminants that need to be characterized for their genetic potential, especially for standard genetic quality by karyotyping. Two important native cattle are Bali and Madura cattle, both of which are derived from banteng (Bos javanicus). Bali cattle are the result of banteng domestication in Java, Bali island and also in some areas of Southeast Asia and Australia. banteng is still found as wild cattle that live in several locations on the island of Java, such as at Ujung Kulon National Park in West Java province and Baluran national park forest at East Java. Bali cattle have spread and are raised throughout almost all provinces of Indonesia. Furthermore, Bali cattle expanded to Malaysia, the Philippines, and Northern Australia. Meanwhile, Madura cattle, a small type of beef cattle, are germplasm suitable, indigenous, and adapted to an arid environment and highly resistant to disease. They have been well developed on the island of Madura, East Java.

Basic genetic information about Indonesian native bull is relatively very limited.The analysis of chromosomes is one powerful method to characterize the genetic normality of animals. Karyotyping of breeding bull and their progeny should be done, because of the importance of chromosome abnormalities and their negative effect on production and reproduction of animals. Chromosomal aberration of a candidate bull can be identified and culled from a breeding program (Achmad et al. 2004). It is necessary that bulls qualified for artificial insemination (AI) must be screened out for any possible chromosomal abnormalities, because a commercial AI bull may be able to produce about 60.000 offsprings per year/bull (Ciptadi et al. 2014). Bali cattle are considered as important genetic resources to Indonesia, because of its high reproductive efficiency, good quality meat and carcass, high carcass percentage, excellent adaptability to the environment and particularly its ability to use a limited feed resource. Madura cattle is the result of cross-breeding of Bali cattle with Zebu (Bos indicus). The diversity of genotypes of Madura cattle is quite high. Chromosomal abnormality could be identified and the affected culled from the breeding population. Abnormal genetics of animals results in reduced fertility in both female and male carriers of the abnormality. Kosarcic et al. (2006) reported that numeric and structural changes on animal karyotype influenced on reproduction, phenotype expression, and selection program. Different aspects of reproductive disturbance include small litter, embryo mortality, frequent repeat breeding, abortion and mummified embryo, offspring with abnormalities and different kinds of sterility.

In Indonesia, AI implementation has been started intensively, especially using imported bulls (Bos taurus) 
i.e. the Limousine breed. Therefore, it is important to execute chromosome analysis on these cattle. Limousine bull is very popular for smallholder farmers in the certain island of Indonesia to cross with local cattle i.e. Madura cattle resulted in very good vital statistic and phenotype of the $\mathrm{F}_{1}$-cross. For the future this situation may be dangerous for maintaining the purity of the Madura breed. It is important to think that cytogenetic control is an important selective measure for choice of genetically healthy breeding bulls, especially for their use AI frozen sperm production. There is no information on the karyotyping of bull classified for AI in Indonesia.

The aim of this study was to perform an analysis of the chromosome and dendrogram of Indonesia native animal with focus on Bali and Madura cattle. This paper presents an analysis karyotyping of the numeric and early structural types of the chromosome of Indonesian native breeds selected for AI. Meanwhile, dendrogram analysis was taxonomical relationship analysis among breeds base on phenotypic specific characters of all Indonesian native breeds of Bali, Madura, PO, and Brahman, compared to Banteng.

\section{MATERIALS AND METHODS}

\section{Animal materials}

A karyotyping was performed on two main native breeds qualified for AI and sperm production. Karyotyping focused on Bali and Madura bulls (3 heads each) and Madrasin (Madura $x$ Limousine cross) females. Dendrogram analysis was performed using specific phenotypic characters observed for parameters of four main local Indonesian breeds, namely Bali, Madura, PO, and Brahman, which were compared to Banteng. These bulls were reared in the AI Centre of Singosari, Malang, East Java, Indonesia.

\section{Karyotyping}

Karyotyping was performed by collecting blood samples from both 2 local breeds (Madura and Bali), 3 bulls each with different phenotypic characteristics. Chromosome analysis was also performed to Madrasin (Madura x Limousin cattle cross). The method for culturing blood cells used was adapted from a combination of several protocols (Miyake, 1985, Ahmad et al. 2004). Each animal's blood was collected in sterile heparinized tubes. A sample of $0.5 \mathrm{ml}$ of blood/animal was added to $5 \mathrm{ml}$ chromosomal medium (Karyo MAX, Gibco), placed in an incubator at $38{ }^{\circ} \mathrm{C}$. After 70 hours, $1 \mathrm{ml}$ colchicines was added to each culture tube and the tubes were kept for 2-3 hours, then were centrifuged at 1000 RPM for 10 minutes and the supernatant was discarded. After fixative solution added then a carnoy solution added to the cell pellet, cell then centrifuged at 1000 RPM for 10 minutes and the supernatant was discarded, this step repeated 3 times. Slides were prepared by dropping the cell suspension $\pm 250 \mu \mathrm{l}$ on the glass slide and drying, then the slides were then stained with Giemsa stain, in order to identify the 30 pairs of chromosomes for normal metaphase scoring. Slides were examined under a high power phase-contrast microscope. The metaphase cells selected for the 10 best spreading metaphase chromosomes were microphotographed and karyotyped. Each chromosome was identified according to International Standard Chromosome Analysis based on order from their specific banding pattern. Chromosomal analysis was performed with the help of cytovision software image analysis (Genus CytoVision Image ver 4.5.1, Genetrix, USA).

\section{Dendrogram analysis}

Dendrogram analysis of phenotypic 4 related breeds (Bali, Madura, PO, and Brahman) compared to banteng was done based on 7 main specific phenotypic characteristics, i.e. dominant skin color, horns, ears, muzzle color, foot color, hump and specific color a part of body. The number of animals used for dendrogram analysis of 4 local breeds (Bali, Madura, PO, and Brahman) is 3 heads each. Meanwhile, Banteng used as a reference is one comes from Baluran National Park, East Java. These consist of 16 sub-specific characters of Bali and Madura cattle compared to their ancestor of Bos javanicus from Baluran National Park and also possibly others breeds considered as their parents, namely Brahman and PO breeds, by Alogaritma: paired group (UPGMA), distance: Euclidean distance $(d)=\sqrt{ }(x 2-x 1) 2+(y 2-y 1) 2$, Cophen Corr: 0.7862. This calculation was used to group members with two or more objects that have the closest similarities. The results were compared to the standard of karyotyping of Bos taurus, Bos indicus and Bos javanicus. Meanwhile, the dendrogram was analyzed descriptively.

\section{RESULTS AND DISCUSSION}

\section{The dendrogram of among Indonesian native breed cattle}

Based on their phenotypic characters, both the Bali and Madura breed were closely related and grouped in one group with their ancestor banteng (Bos javanicus) compared to PO breed, which grouped with Brahman cattle (Figure1). Both Madura and Bali cattle showed higher genetic distance with banteng in cluster $\mathrm{A}=$ banteng and Bali cattle displayed a genetic distance equal to 2,83 . Meanwhile in cluster B $=$ PO displayed genetic distance of 2.45 with Brahman cattle. The Madura cattle have a closer similarity to Cluster A (Table 1).

\section{Chromosome analysis result in Bali and Madura cattle}

In general, karyotyping of Madura and Bali candidate bulls used for AI and Madrasin (Madura x Limousin) cows categorized them as having normal chromosome numbers and structure (Figures 2, 3 and 4).

The $2 \mathrm{~N}$ diploid numbers of chromosomes of both local cattle breeds were normal number of 60, 58 autosomal and 2 sex chromosomes in all cattle observed. It was observed that Bali and Madura bulls tested were normal. The karyotype analysis showed that the chromosomes of one cell and different individual each breed varied in size, shape, and position of the centromere within a biarmed 
chromosome, in addition to the $\mathrm{X}$ and $\mathrm{X}$ or $\mathrm{Y}$ (Figure 2 and 3 ). The sex chromosome for bulls, the X-chromosome was the largest-submetacentric chromosome, while the Ychromosome was the smallest-acrocentric chromosome. Some of the variation may be caused by physical factors during fixation or chromosome spreading (Figure 3 and 4).

\section{Discussion}

The results of our study of cattle chromosomes are similar to those of other researchers (Anis et al. 1990, Lio et al. 1995) that studied various breeds and reported that cattle have 60 chromosomes. All of the 30 pairs displayed G-banding patterns (shows in black and white after a photograph) characteristic of good quality chromosomes (Figure 1). With the help of cytovision software, the autosome and sex chromosome could be identified by their numbers, size and banding patterns. In a case of Madura cattle, chromosome analysis is very important, because in the past ten years, this breed has been crossed with a foreign breed of Bos taurus, i.e. Limousine to increase cattle production (Ciptadi, 2014), which may influence their genetics, reproductivity, and productivity. This cytogenetic test should be implemented, because of the importance of chromosome abnormalities that may have negative effects on production and reproduction performances. There are many types of chromosome abnormalities in domestic animals, and these abnormalities are closely related to the reproductive disorders (Miyake, 1996, Gallagher et al. 1999, De Luca et al. 2007, Anis et al. 1990). For instance, Schmutz et al. (1997) described reduced fertility in female carriers of the $\operatorname{rob}(1: 29)$ translocation. The rob $(1 ; 29)$ translocation has spread to all European cattle breeds and, eventually, to the rest of the world through cross-breeding, with-out appearing ex-novo and the distribution of the rob $(1 ; 29)$ Robertsonian translocation was analyzed to determine whether this polymorphism contributes to the low reproduction efficiency observed in five endangered Andalusian (Spanish) cattle breeds (Serrano et al. 2013 ). Chromosomal abnormalities in the sex chromosome pair are widely associated with reproductive problems in horses (Anaya et al. 2017). Cytogenetic studies in Polish Blackand-White bulls showed the existence of two morphological forms of Y chromosome. Among the 22 karyotypically analyzed bulls, 12 had submetacentric and 10 metacentric Y chromosome (Parada et al. 2017).

This technique of karyotyping may be very valuable in the cytogenetical analysis of chromosomal abnormalities. Cytovision software is very helpful for producing more accurate results. With cytovision analysis tools counting/numbering of metaphase chromosomes with segmentation (split, overlapped, and joined) was possible. The cytogenetic analysis and control are an important selective measure for choosing genetically health candidate of breeding bulls or artificial insemination (AI) is important to perform. Based on the presence of a chromosomal aberration, a candidate bull can be identified and culled from a breeding program. For local Indonesian cattle, as well as other local animals, we proposed to use this test as a new criterion of selection to of candidate sires, especially for AI commercial sperm production, (Ciptadi et al. 2017). Ahmad et al. (2004) mentioned that screening of breeding bulls of different breeds through karyotyping is important, especially bulls maintained at semen production units or Artificial Insemination Centers. Karyotyping is one amongst different culling parameters. Chromosomal screening is beneficial in the selection of superior animals.

Table 1. Data on phenotypic characters of Indonesian native bull (for dendrogram)

\begin{tabular}{|c|c|c|c|c|c|c|}
\hline Main Traits & Traits & Banteng & Bali & Madura & PO & Brahman \\
\hline \multirow[t]{12}{*}{ Colour } & Major body & Dark Brown & Sorrel & Sorrel & White Greyish & White \\
\hline & Front ankle & White & Sorrel & Sorrel & White & White \\
\hline & Head & Cokelat Tua & Sorrel & Sorrel & White & White \\
\hline & Whites around eyes & Yes & Yes & Yes & Darken & No \\
\hline & Butt & White & White & Sorrel & White & White \\
\hline & Back ankle & White & White & White & White & White \\
\hline & Backline & White & Dark & Sorrel & Dark & White \\
\hline & Whites around mouth & Yes & Yes & Yes & Yes & Yes \\
\hline & Major hump & Dark Brown & Sorrel & Darken Sorrel & White & Dark \\
\hline & Dark muzzle & No & Yes & Yes & Yes & Yes \\
\hline & Dark nail & Yes & Yes & Yes & Greyish & White \\
\hline & Around neck major & Yes & Yes & Yes & Yes & Darken \\
\hline \multirow[t]{3}{*}{ Horn } & Shape & Curved & Slightly curved & Straight & Straight & Doward curved \\
\hline & Size & Long & Middle & Short & Short & Short \\
\hline & Types & Upward & Upward & Backward & Backward & Downard \\
\hline \multirow[t]{2}{*}{ Ears } & Shape & Straight up & Straight up & Straight up & Lop-eared & Lop-eared \\
\hline & Inner colour & White & White & White & White & White \\
\hline \multirow[t]{3}{*}{ Hump } & Clearly & No & No & Yes & Yes & Yes \\
\hline & Size & Small & Small & Middle & Big & Big \\
\hline & Colour & Dark Brown & Sorrel & Darken sorrel & White & Dark \\
\hline \multirow[t]{2}{*}{ Dewlaps } & Hanging & Yes & Yes & Yes & Yes & Yes \\
\hline & Size & Small & Small & Middle & Big & Bigger \\
\hline
\end{tabular}




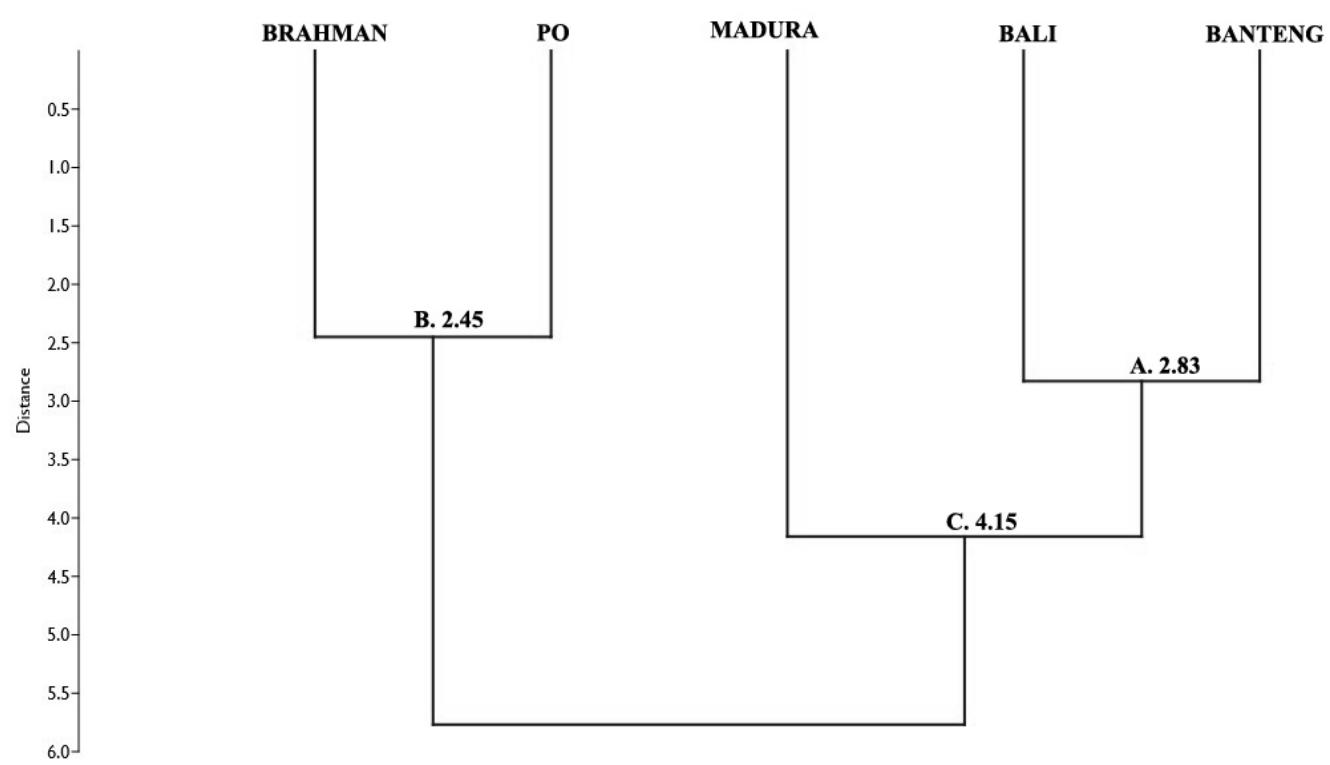

Figure 1. Dendrogram analysis of Bali and Madura cattle compared to other local breeds found in Indonesia namely PO (Java cattle) and Brahman. Madura and Bali's cattle were derived from banteng which may cross with Java cattle (Brahman and PO cattle). The genetic distance and clustering of each breed with wild banteng (Bos javanicus) are indicated that cluster $\mathrm{A}=2.83, \mathrm{~B}=2.45$ and $\mathrm{C}=4.15$ respectively

The early analysis of G-banding preparation showed in some improper preparation; a clear banding pattern sometimes could not be obtained, because the bands were unclear or were too close each other. The technique of photography and manual karyotyping also provided less support for these analyses. Yamanaka (1977) suggested that in order to identify each chromosome for karyotype analysis in cattle, the number, intensity, width, and disposition of each band, as well as size of chromosomes should be considered. However, Ciptadi et al. (2017) suggested that in developing countries, Indonesia especially, where AI implementation has been started, at national or state levels especially in Artificial Insemination Center, it is necessary to introduce this karyotyping in selection programs, for chromosomal control of breeding males. Karyotyping is one amongst several culling parameters and could be used as an indicator of genetically normal bulls, because each can produce a large number of offspring per year/bull. Artificial Insemination is not only beneficial as a means of reproduction and raising the population but also aids efforts to improve the genetic quality of local livestock (Ciptadi et al. 2014).

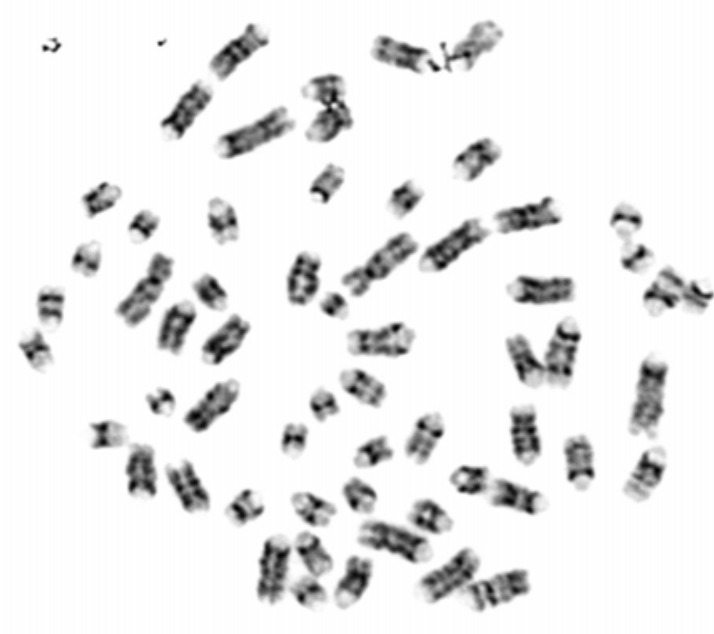

A

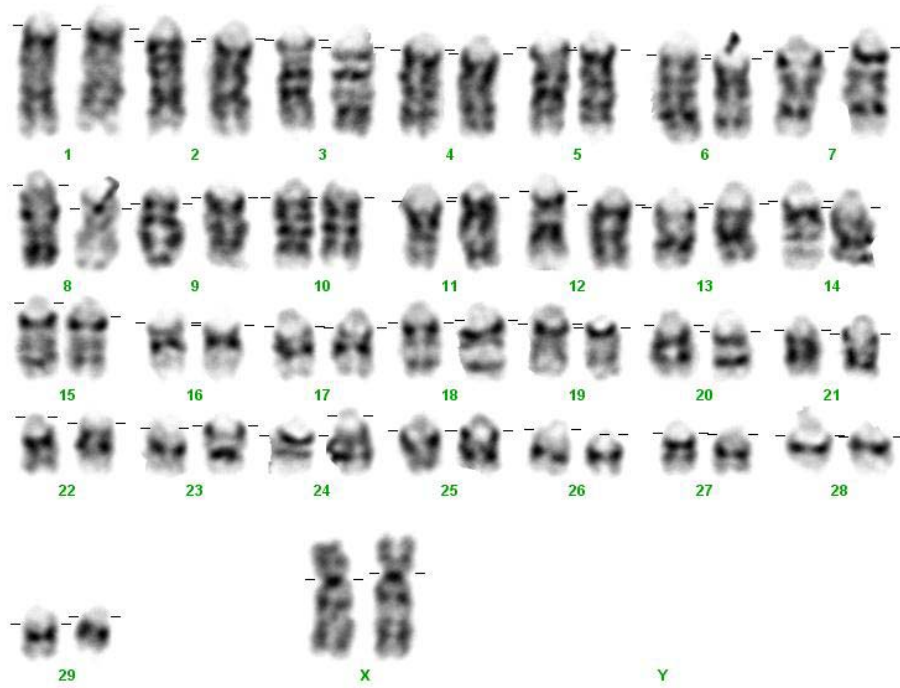

B

Figure 2. Cattle chromosome (female) of $F_{1}$ Madura $x$ Limousine cattle cross (Madrasin), showed normal numbers of 30 pairs chromosomes: A. Spreading chromosomes resulted in different size and shape of chromosomes. (1000 x). B. Karyotyping of images using cytovision software. The number of chromosomes was considered normal $2 n=60$ ) 


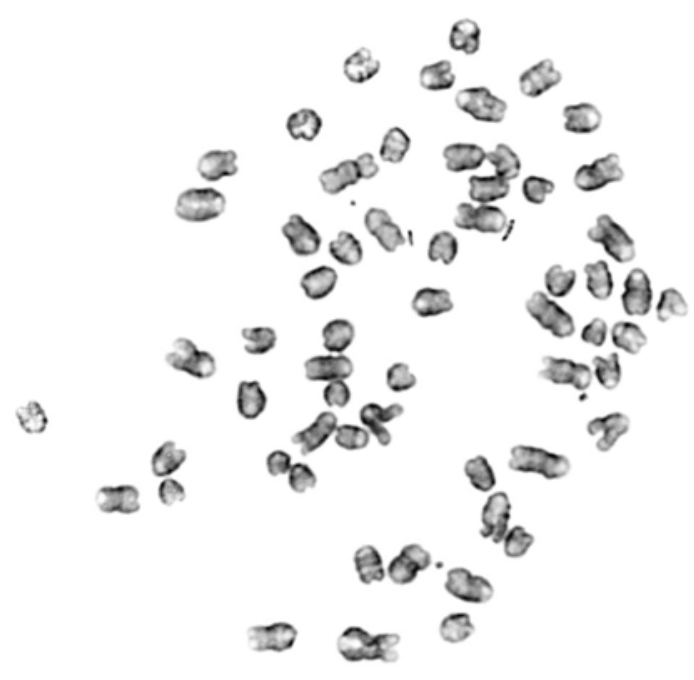

A

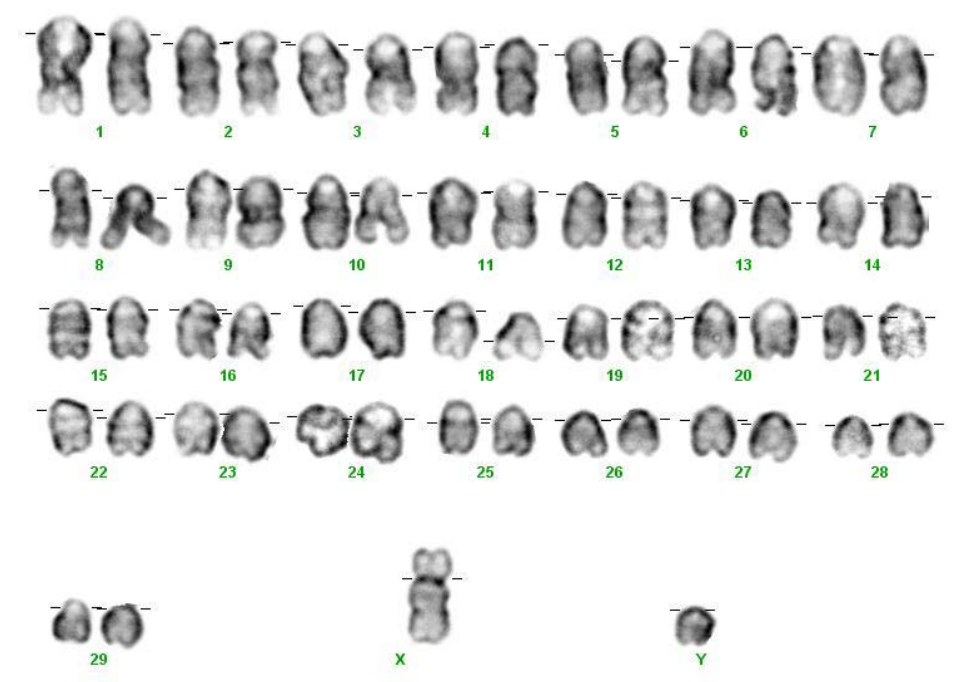

B

Figure 3. Cattle chromosome (male) of Madura cattle, showed normal numbers of 30 pairs ( $2 n=60)$. A. Spreading chromosome resulted in different size and shape of chromosomes $(1000 \mathrm{x})$, B. Karyotyping of Madura bull. using software image of cytovision (Genetrix, USA)

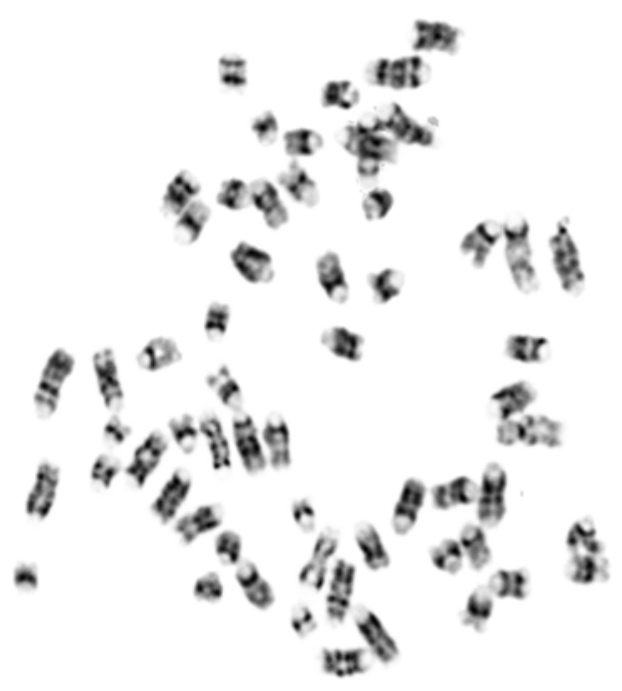

A
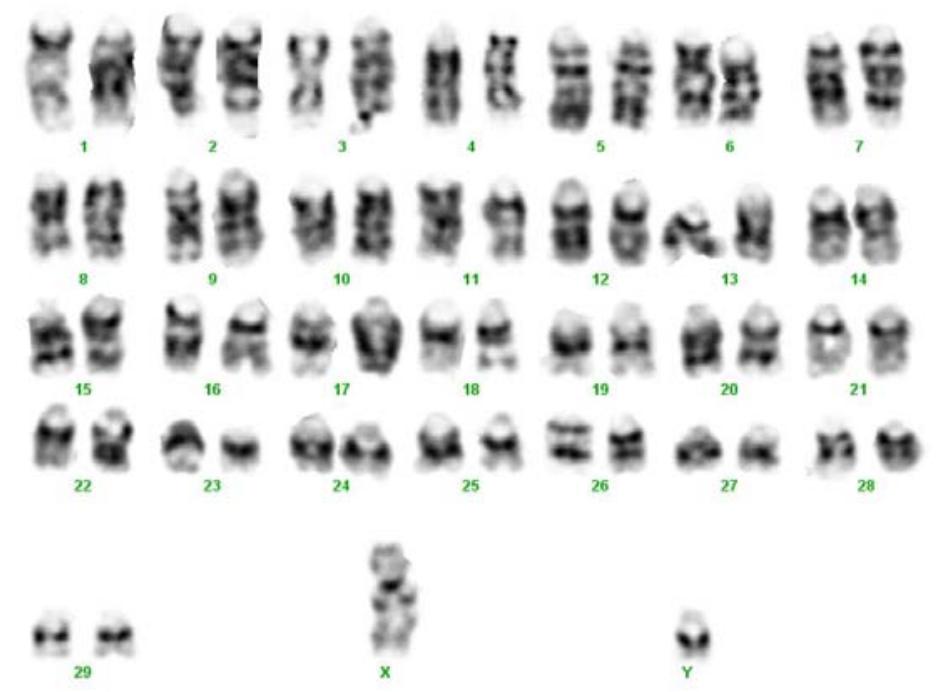

B

Figure 4. Cattle chromosome of Bali bull, showed a normal number of 30 pairs. A. Spreading chromosome (1000x) and B. Karyotyping of Bali bull

Abnormal genetics could contribute to reduced fertility in both female and male carriers of this abnormality. Kosarcic et al. (2006) reported that numeric and structural changes ion animal karyotypes influenced on reproduction disturbance, phenotype expression, and selection programs. The information obtained related to Madrasin cattle, a descendant of Madura and Limousine breeds, may be of benefit to a large number of cattle breeders or smallholder farmers to improve their animal genetics quality and productivity. Yimer and Rosnina (2014), mentioned that chromosome abnormalities in cattle could cause significant adverse effects on fertility through failure of production of viable gametes or early embryonic death that consequently leads to great economic loss. Chromosomal aberrations can occur as numerical errors or structural rearrangements usually without causing phenotypic abnormalities in carrier animals.

The dendrogram analysis indicated that banteng with Bali cattle form in one cluster (Cluster A), while PO and Brahman cattle form another closely related cluster (Cluster B). Madura cattle have a closer distance to Cluster A. Cluster B has the higher value similarity compared to 
Madura cattle and cluster A. Historically, it was mentioned that Bali cattle and Madura were derived from banteng (Bos javanicus), which still exist in Java in part east of Baluran national forest parks, East Java province and west part of Ujung Kulon national park area, West Java province of Java island. It could be interpreted that Madura and Bali cattle was very possibly derived from banteng, which may have crossed with Brahman and PO.

It was concluded that the karyotyping performed on Bali and Madura's bull used for AI indicated that they fall in the normal category. It was very important to perform this chromosomal investigation of all candidate breeding bulls before using these bulls for commercial AI semen production. It is recommended to perform chromosomal investigation of all local candidate breeding animals of an important Indonesia local breed, especially those to be used for AI in the near future. It is necessary that candidate Bali and Madura bulls for AI must be screened to cull out any chromosomal abnormalities.

\section{ACKNOWLEDGEMENTS}

These works were supported by a Research Grant of HIKOM year 2014/2015/2016 from the Directorate General of High Education, Ministry of Education, Republic of Indonesia (KEMENSISTEK DKTI). Contract No.: 530.201/UN10.21/PG/2015, 18 Mei 2015. We are grateful to Prof. James R. Ketudat-Cairns from the Institute of Science Suranaree University of Technology, Thailand for kindly correcting the English of this manuscript.

\section{REFERENCES}

Ahmad IK, Javed, Sattar A. 2004. Screening of breeding bull of different breeds through karyotyping. Pakistan Vet J 24 (4): 190-192.

Anaya G, Molina A, Valera, Moreno-Millan M, Azor P, Peral-Garcia P, Demyda-Peyras S. 2017. Sex chromosome abnormalities associated with equine infertility: validation of simple molecular screening tool in the Purebred Spanish Horse. J Anim Genet 48 (4): 412-419.
Anis M, Ali S, Ahmad Z, Khan MA. 1990. Studies on the karyotypes of Sahiwal cattle. Pakistan Vet J 10 (2): 88-91.

Chamdi AN.2005. Review: The characteristics of genetic resource of Bali cattle (Bos-bibos banteng) and the alternative of it's conservation methods. Biodiversitas 6: 70-75.

Ciptadi G, Ihsan MN, Rahayu S, Budiarto A, Wahjuningsih S, Nasich M, Karima NK, Mudawamah M, Ardyah IP, Ramadhina. 2017. The comparison of goat chromosome analysis result using simple G banding by manual and software cytovision image analysis. Res $\mathrm{J}$ Life Sci 4 (2): 106-110.

Ciptadi G, Ihsan MN, Nurgiartiningsih VMA, Mudawamah M. 2014. The karyotyping of Indonesia local cattle and buffalo for genetic quality standardization of chromosome aberration. Proc. International Seminar. The 16th Asian-Australian Association of Animal Production Societies. The 16th AAAP Congress. UGM Jogjakarta, 2014.

De Luca JC, Sister P, Prando A, Baldo A, Giovambattista G. 2007. The absence of 1/29 translocation in Aberdeen Angus breed. J Analecta Veterinaria 27 (2): 25-27

Gallagher DS, Lewis Jr BC, De Donato M, Davis SK, Taylor JF, Edwards JF. 1999. Autosomal trisomy $20(61, \mathrm{XX},+20)$ in malformed bovine fetus. Vet Pathol 36: 448-451.

Innayah, Fiona H. 2011. The characteristic environment of banteng (Bos javanicus d'Alton 1832) in Meru Betiri National Park, East Java. [Hon. Thesis] Department of Forest Conservation Resources and EcoTourism, Faculty of Forestry, Bogor Agricultural University, Bogor. [Indonesian].

Kosarcik S, Kovacevic M, Jovicin M, Zivkoz Balos M, Kosarcik D.2006. Changes in karyotype in domestic animals discovered on the farms in Vojvodina and their influence on reproduction. J Genet 39 (2): 121128.

Lioi MB, Scarfi MR, Di Berardino D.1995. An autosomal trisomi in cattle. Genet Select Evol 27: 437-476.

Miyake YI.1996. Study on reproductive disorders related to chromosome abnormalities in domestic animals. J Reprod Dev 43 (6): 111-118.

Parada R, Kawka M, Sacharczuk M, Urbanski P, Jaszczak K. 2017. Cytogenetic and genetic study of a Y-linked microsatellite polymorphism in Polish black-and-white cattle breed. Saudi J Biol Sci. DOI: 10.1016/j.sjbs.2017.01.053.

Schmutz SM, Moker JS, Pavlyshyn V, Haugen B, Clark EG. 1997. Fertility effect of the 14; 20 Robertson Ian translocation in cattle. J Theriogenology 47 (4): 815-823.

Serrano ER, Peyrás SD, Martinez AG, Franganillo AR, Millán MM. 2013. The rob $(1 ; 29)$ Chromosome translocation in endangered Andalusian cattle breeds. Livestock Sci 158. 32-39.

Yamanaka H.1977. The possibility of cattle chromosome classification, identified by G-banding patterns. Japanese J Vet Res 25: 52-58.

Yimer N, Rosnina Y. 2014. Chromosomal anomalies and infertility in farm animals: A review. Pertanika J Trop Agric Sci 37 (1): 1-18. 